Historic, Archive Document

Do not assume content reflects current scientific knowledge, policies, or practices. 



\section{GLADIOLUS GOLD}

/8

\section{A new, rich golden yellow variety, originated by Dr. C. HOEG (Decorah Gladiolus Gardens.)}

Pure golden yellow, throat a shade deeper, slightly dotted and streaked, almost self-color. Large flowers, many open at one time and perfectly placed. An exceedingly beautifull spike. Stem always straight. Quite early.

\section{Awarded first price, Boston, 1921.}

\section{STRONG ENDORSEMENTS BY MANY WELL KNOWN EXPERTS:}

"I think you are entirely too modest in your claims about a lot of your varieties, especially GOLD. I haven't seen a yellow, shown in the East, that can approach it in color, shape or texture, with the possible exception of Golden Measure at its best. The dotting and stripeing in the throat is almost imperceptible. It is nearly a perfect self, of glorious shade, and this, coupled with the extreme earlyness and multiplying quality, makes it without very little question the most valuable yellow gladiolus in the world to-day."-A. L. STEPHEN, Waban, Mass.

"GOLD did exceptionally fine this season (1920) here. In many respects I prefer it to Golden Measure; it is a clearer yeilow and of a different type than Golden Measure and is a worthy companion of that superb variety. These two yellow gladioli should be in every collection and to my knowledge are far superior to any yellows that have been offered to the public."-C. Fred Boshart, Lowville, N. Y

"I want to say, I never saw anything to beat the blooms I had of GOLD. They were far better than anything I have yet seen in yellow-better than Golden Measure,"-J. C. Crombie, St. Thomas, Ontario.

"I must congratulate you on having produced such a beautiful and useful glad as GOLD. I have grown it almost side by side with all the best yellow varieties and like it best of all. Every grower I have mentioned Gold to believes it to be the finest ever produced. It will be known and grown everywhere."-Stanley Thorpe, Medway R. D., Mass.

"Your GOLD at the Boston show made a real hit. It was fine and very generally appreciated." -Rev. Frederic W. Blakeslee, Roslindale, Mass.

"Your GOLD, to my mind, is the finest yellow I have ever seen. It has grown from a small bulb a most superior flower, that looks right at you. It certainly has a great future."-Benjamin $R$. Norley, Roslindale, Mass.

"I have seen your GOLD at two shows and it was the ONLY yellow there - Golden Measure is not in it."-J. L. Vondel, Sharon Heights, Mass.

"I think GOLD is the best yellow I have yet seen. Golden Measure alongside of it looks very flat indeed."-E. P. Hawes, Roslindale, Mass.
"I consider GOI.D one of the most valuable yellows yet produced, as it has a purity of color unsurpassed by any other yellow that I have yet seen."-Howard M. Gillet, Lebanon Springs, N. Y.

"We would advise you to hold GOLD, as we consider it better than Golden Measure."-E. M. Smith, Pres. East Hartford Gladiolus Co., East Hartford, Conn.

"We had nearly everybody in Lansing raving over the few spikes of GOLD we had in bloom last year." -L. W. Hoisington, Lansing, Mich.

"The exhibition at the Boston show of your GOLD was certainly one to be proud of."-M. A. Reed, Cambridge, Mass.

"I want to assure you that GOLD is the coming yellow. Did I write you, that I thought it would be unbeatable in a cold season? I am led to make that remark because one spike which came a month after all the others were gone was the most magnificent thing that I have ever seen."-A. L. Stephen, Waban, Mass.

\section{And again:}

"GOLD is surely 24 carats fine and only Golden Measure AT ITS BEST can touch it."-A. L. Stephen, Waban, Mass.

\section{And again:}

"I compared GOLD and Golden Measure at the show (Boston, 1921) and were I a judge I surely would give it to Gold. I grew G. M. for the first time this year and had a glorions spike but Gold was still better. Then I like the shape better. G. M. has a trifle the better growth but Gold is big enough, in fact nearly perfect."-A. L. Stephen, Waban, Mass. 
